\title{
Design of Printed CPW-fed Monopole Antenna for WiMAX and WLAN Dual Band-Notched Characteristics for UWB Applications
}

\author{
B. Satyanarayana ${ }^{1 *}$ and S. N. Mulgi ${ }^{2}$ \\ ${ }^{1}$ Department of Electronics Engineering, Indian Institute of Technology (BHU), Varanasi - 221 005, Uttar Pradesh, India \\ ${ }^{2}$ Department of Postgraduate Studies and Research in Applied Electronics, Gulbarga University, Kalaburagi-585 106, \\ Karnataka, India \\ *satya.gug@gmail.com
}

\begin{abstract}
A printed CPW-fed monopole antenna with dual band-notched characteristics for UWB applications is presented in this paper. By etching both inverted elliptical split ring slots on the radiating patch dual band-notched characteristics are obtained a narrow bandwidth at 3.3-3.8 GHz for WiMAX (3.3-3.7 GHz) and for WLAN (5.725-5.825 GHz) operating bands are achieved. The physical structure of the proposed antenna is printed on the $28 \mathrm{~mm} \times 34 \mathrm{~mm} \times 1.6 \mathrm{~mm}$ size FR-4 dielectric substrate. The presented antenna has a wide impedance bandwidth of 2.89 to more than $14 \mathrm{GHz}$ expect of two notch bands. The antenna operates for the entire UWB (3.1-10.6 GHz) range and gives omnidirectional radiation patterns and stable peak gain expect at the band-notched frequencies. The proposed antenna has a planar geometry which is a good choice for any portable UWB communication system applications.
\end{abstract}

Keywords: Planar monopole antenna, dual band-notched, UWB, elliptical split ring slot, WiMAX, WLAN

\section{Introduction}

Since the U.S. Federal Communications Commission (FCC) is allocated the $3.1-10.6 \mathrm{GHz}$ frequency band for commercial applications of ultra-wideband (UWB) communication system [1] in 2002. The more concentration has been paid on UWB technology due to many technological advantages such as short range high secure data transmission, low power consumption, etc.[2]. For the practical reliable use of the UWB communication technology the important device must be a planar structure with wide impedance bandwidth requirement. One of the demerits of the UWB communications is suffering from existing frequency bands such as Bluetooth $(2.2-2.4 \mathrm{GHz})$, WiMAX (3.3-3.7 GHz), IEE802.11a/b WLAN (5.15-5.35 $\mathrm{GHz}$ and $5.725-5.825 \mathrm{GHz}$ ) at the time of use. To overcome this serious problem, the good omnidirectional radiation characteristic UWB antenna with band-notched features is desirable.

In recent years, the many technical reports on band notched UWB antennas have been reported. The simple techniquse to implement the band-notched characteristics includes use of different geometries of radiating patch with embedding slots [3-6], inserting slits on both radiating patch and ground plane [7-9], using parasitic strips and resonators to radiating patch, etc. [10-12].

In this paper, a planar printed CPW-fed monopole antenna with dual band-notched characteristics is presented. The proposed UWB antenna consists of a truncated disk radiating patch with a pair of elliptical split-ring slots which covers the range from 2.89 to more than $14 \mathrm{GHz}$. By etching optimum dimensions of both elliptical split ring on the upper and lower side of the radiating patch the dual notch bands are achieved. The performance of the antenna design the simulated VSWR, current distributions radiation patterns and gain are presented and discussed.

\section{Antenna Design}

The geometry of the dual band-notched UWB antenna is illustrated in Figure 1. The antenna is fabricated on a lowcost FR-4 dielectric substrate having a relative permittivity $\left(\varepsilon_{\mathrm{r}}\right)$ of 4.4 , loss tangent $(\tan \delta)$ of 0.02 and a substrate thickness (h) of $1.6 \mathrm{~mm}$. The proposed antenna is consists of a disk radiating patch with a pair of elliptical split-ring slots and a partial finite-size ground plane on either side of the $50 \Omega$ CPW transmission line. The disk radiating patch basically a circle with radius of $7.9 \mathrm{~mm}$ which is truncated the side and top edges. A truncating area with a size of $\mathrm{T}_{1}$ and $\mathrm{T}_{2}=9.24 \mathrm{~mm}$ and $\mathrm{T}_{3}=11.9 \mathrm{~mm}$ are maintained which provides a mechanism to enhance the impedance bandwidth with VSWR $\leq 2$ over the UWB range. Moreover, in order to achieve an optimum impedance matching between a ground plane and $50 \Omega \mathrm{CPW}$ microstripline the distance $\mathrm{g}=0.37$ $\mathrm{mm}$ and $\mathrm{d}=0.65 \mathrm{~mm}$ is maintained between radiating patch and $50 \Omega \mathrm{CPW}$ microstripline. The entire antenna structure is printed within a small size of $26 \times 32 \mathrm{~mm}^{2}$ substrates. A simple $50 \Omega \mathrm{CPW}$ microstrip line feed with a length $\mathrm{L}_{\mathrm{f}}$ $=15.15 \mathrm{~mm}$ and $\mathrm{W}_{\mathrm{f}}=3.07 \mathrm{~mm}$ is selected to excite the antenna. Further, to obtain WiMAX and WLAN dual notched-band characteristics a pair of elliptical split-ring slots is loaded onto the radiating patch. With a slight change of total length of the elliptical split-ring slots, it is easy to adjust the center frequencies of the notched-bands at particular frequency range.

Finally, optimized design parameters of the antenna are depicted as follows: $\mathrm{T}_{1}$ and $\mathrm{T}_{2}=9.24 \mathrm{~mm}, \mathrm{~T}_{3}=11.9 \mathrm{~mm}$, $\mathrm{e} 1_{1}=26.06 \mathrm{~mm}, \mathrm{e} 2_{1}=19.09 \mathrm{~mm}, \mathrm{e} 1_{\mathrm{w}}=0.61 \mathrm{~mm}, \mathrm{e} 2_{\mathrm{w}}=0.65$ $\mathrm{mm} \mathrm{g}=0.57 \mathrm{~mm}, \mathrm{~d}=0.65 \mathrm{~mm}, \mathrm{~L}_{\mathrm{f}}=15.15 \mathrm{~mm}, \mathrm{~W}_{\mathrm{f}}=3.07 \mathrm{~mm}$, $\mathrm{L}_{\mathrm{g}}=14.5 \mathrm{~mm}$. The photograph of top and bottom view of dual band-notched UWB antenna is given in Figure 2. The variation of voltage standing wave ratio (VSWR) versus frequency of the proposed antenna is tested successfully 
using Rohde \& Schwarz ZVK model 1127.8651 German make Vector Network Analyzer (VNA). The other results such as radiation characteristics, surface current distributions, gain and antenna efficiency and group delay variation are presented and discussed.

\section{Results and Discussion}

The design of the proposed dual notched-band antenna, simulation VSWR plots, current distributions, gain and the parametric study for better understanding the effect of dual notched-band characteristics are studied by the commercial electromagnetic High Frequency Structure simulator (HFSS) [13].

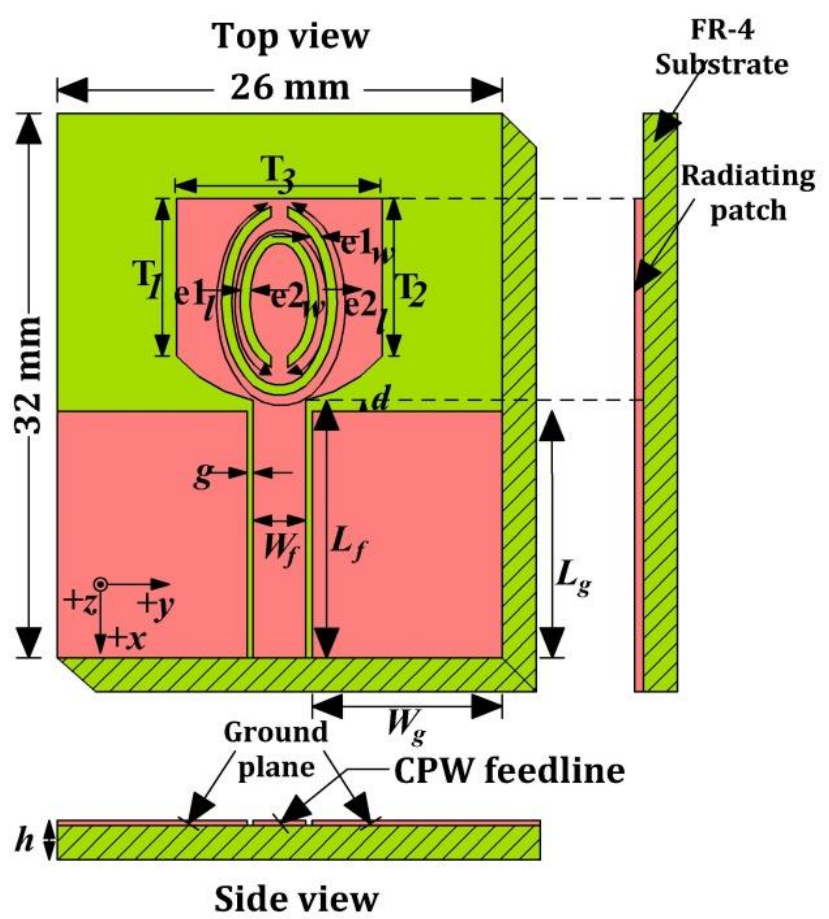

Fig.1 Geometry of the dual band-notched UWB antenna

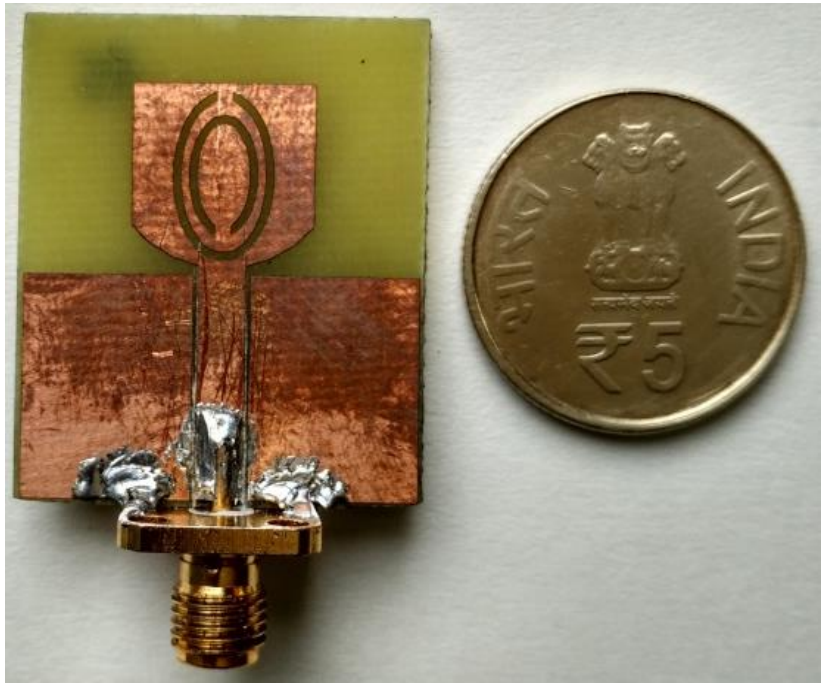

Fig. 2 Photograph of the dual band-notched UWB antenna
Figure 3 shows a comparison of measured and simulated VSWR curves of the proposed antenna. From this figure, it can observe that the measured VWSR is in good agreement with the simulated one. The antenna rejects the bandwidth of WiMAX and WLAN which covers the frequency range from 2.89 to more than $14 \mathrm{GHz}$ for $\mathrm{VSWR} \leq 2$ covering the entire UWB (3.1-10.6 GHz) frequency band. Hence, this antenna rejects the interference of WiMAX (3.3-3.7 GHz) and WLAN (5.725-5.825 GHz) bands.

Figure 4 shows the simulated surface current densities $(\mathrm{A} / \mathrm{m})$ of the proposed antenna at frequencies 3.3 and 5.75 $\mathrm{GHz}$ and are shown in Fig. 4(a) and (b) respectively. It can be observed from the Fig.4 (a) that, the surface current densities at $3.3 \mathrm{GHz}$ is mainly distributing around the edges of the bigger size elliptical split-ring slot whereas the surface currents densities at $5.75 \mathrm{GHz}$ is mainly accumulating along the edges of the lower size elliptical split-ring slot which is shown in Fig.4 (b). Also, from these figures, it is well known that the proposed antenna shows a dual notched-band feature at WiMAX (3.3-3.7 GHz) and WLAN (5.725-5.825 GHz) within the UWB band. Further, the $3 \mathrm{D}$ radiation patterns which are measured at $3.3 \mathrm{GHz}$ and $5.75 \mathrm{GHz}$ also represent that, at the notched bands there is less energy is observed due to notch property.

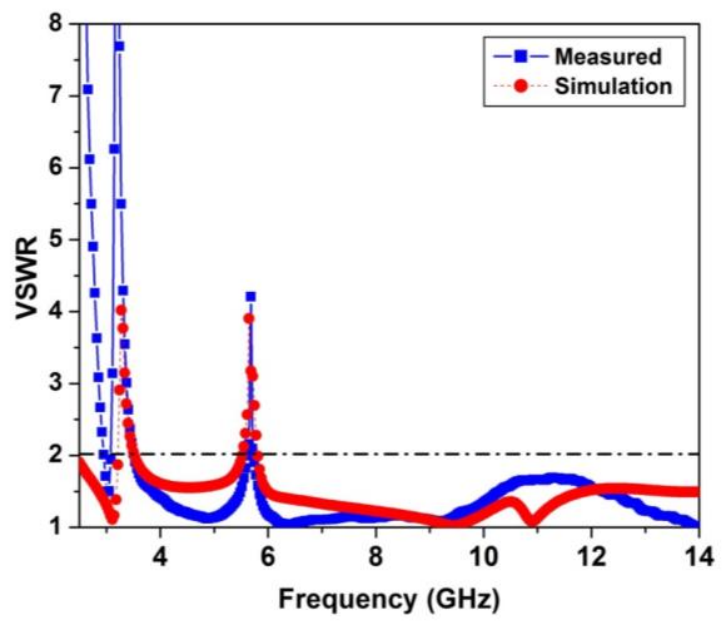

Fig. 3 Measured and simulated VSWR plots of dual band-notched UWB antenna

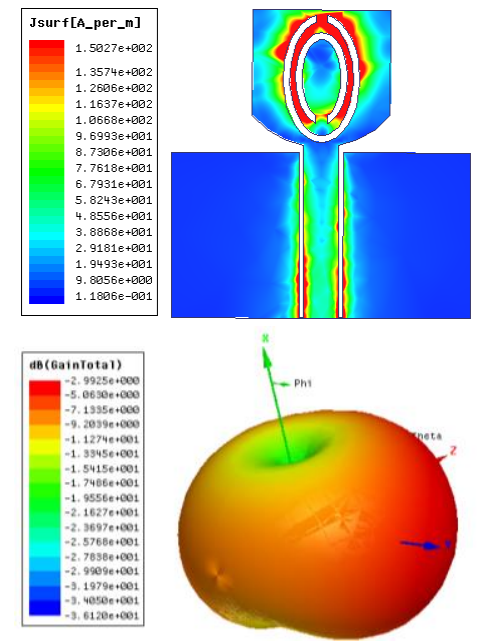

(a) 


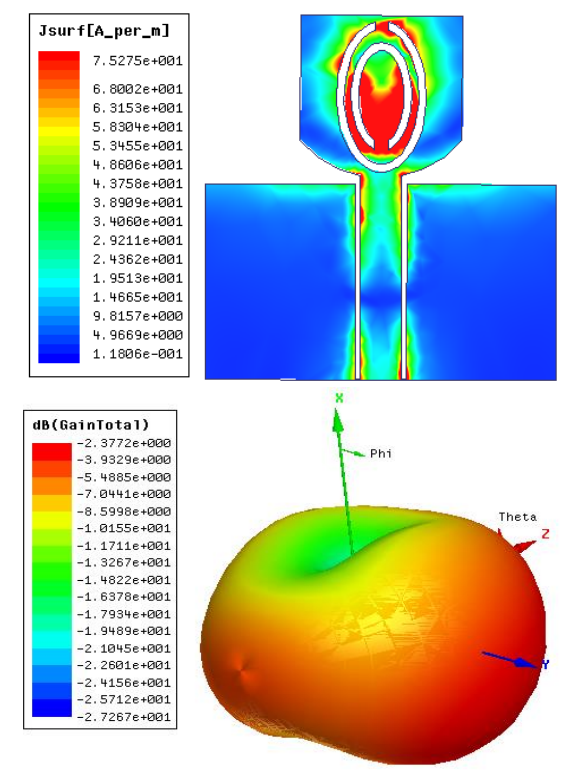

(b)

Fig. 4. Surface current distributions and $3 \mathrm{D}$ radiation patterns of proposed antenna at (a) 3.3 and (b) $5.75 \mathrm{GHz}$

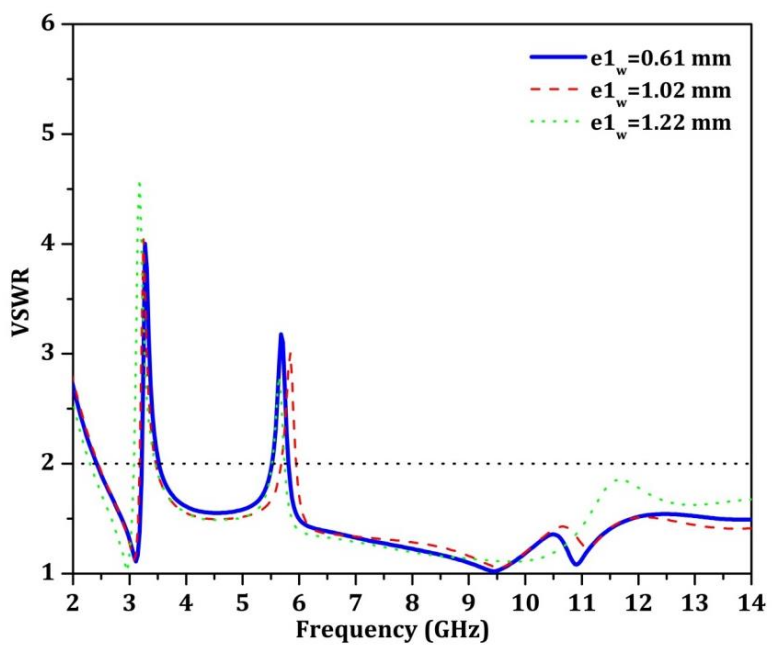

Fig. 5 Simulated VSWR curves for the different values of $\mathrm{e} 1_{\mathrm{w}}$

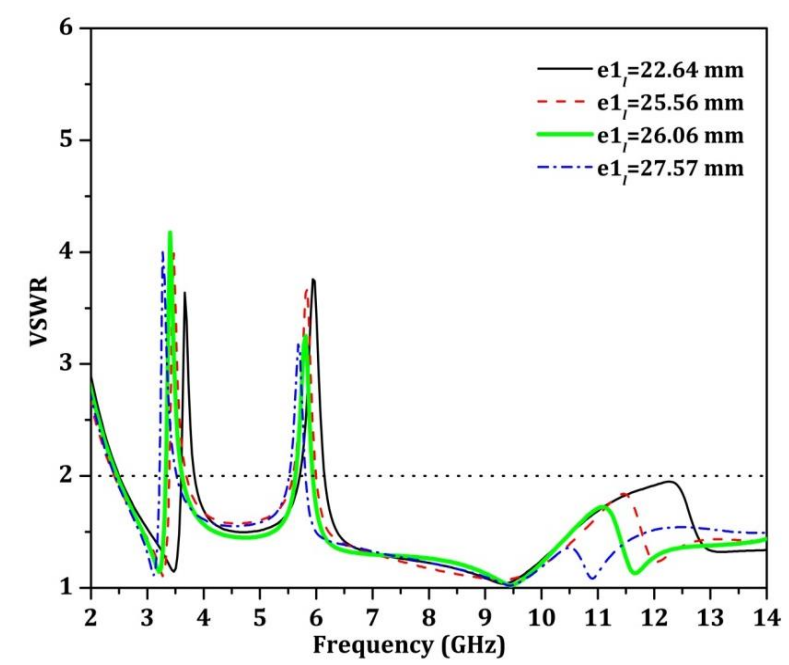

Fig. 6 Simulated VSWR curves for the different values of $1_{1}$
The parametric study of the dual band-notched UWB antenna is analyzed to understand the dual notched-band characteristics by changing one parameter at a time and keeping other parameters as constant. The simulated results are obtained using the ANSYS high-frequency structure simulator (HFSS) simulation software.

Figure 5 exhibits the effect of bigger elliptical split-ring slot widths $\mathrm{e} 1_{\mathrm{w}}$ on VSWR curves. A center notch frequency shift from $3.2 \mathrm{GHz}$ to $3.4 \mathrm{GHz}$ corresponds to the changing of the bigger elliptical split ring slot width from $0.61 \mathrm{~mm}$ to $1.22 \mathrm{~mm}$. Figure 6 shows the VSWR curves of the proposed antenna by varying the big elliptical split-ring slot lengths e11. From Fig. 6, it is observed that the central frequency of the notched band is controlled by the length of the elliptical split-ring slot. When the length of the elliptical split-ring slot varies from $22.64 \mathrm{~mm}$ to $27.57 \mathrm{~mm}$ the frequency shifts from around 3.2 to $3.65 \mathrm{GHz}$ without disturbing the upper notched band.

Similarly, the effect of simulated VSWR plots for different values of $\mathrm{e} 2_{\mathrm{w}}$ is shown in Fig. 7. It is observed from this figure that, by increasing the width of the smaller elliptical split-ring slot values e $2_{\mathrm{w}}$ from $0.54 \mathrm{~mm}$ to $1.07 \mathrm{~mm}$ and by keeping the e $2{ }_{1}$ value is constant, the center frequencies of the corresponding notched-band shifts towards the lower frequencies of $5.6 \mathrm{GHz}$ to $5.95 \mathrm{GHz}$. Figure 8 shows the simulated VSWR plots for different values of e2. By increasing the e2 from $15.55 \mathrm{~mm}$ to 19.09 $\mathrm{mm}$, the notch frequency is varied from $5.75 \mathrm{GHz}$ to 6.8 $\mathrm{GHz}$.

In addition, it is noticed from the above results that, the lengths and widths of the corresponding slots and by adjusting the one parameter keeping the other parameters constant, only the corresponding notched band changes without disturbing the other notched-band. When the total lengths of the slots are approximately equal to a half wavelength, the optimal notched-band characteristics can be achieved. The proposed antenna design the optimal values of the elliptical split-ring slots $\mathrm{e} 1_{\mathrm{w}}, \mathrm{e} 1_{\mathrm{l}}, \mathrm{e} 2_{\mathrm{w}}$, and $\mathrm{e} 2_{1}$ are chosen as $0.61 \mathrm{~mm}, 26.06 \mathrm{~mm}, 0.65 \mathrm{~mm}$ and 19.09 respectively which approximately determines the center frequencies of the desired notched-bands of WiMAX and WLAN.

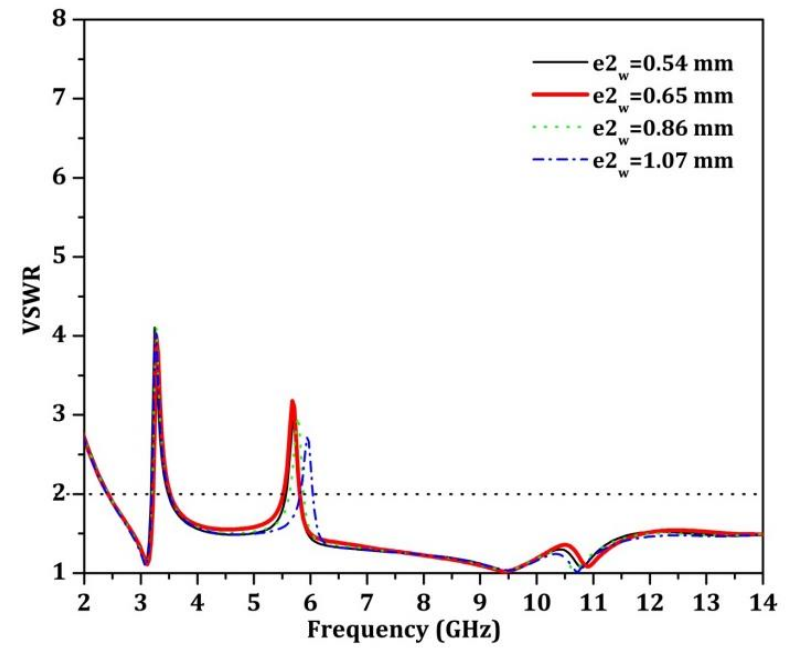

Fig. 7 Simulated VSWR curves for the different values of $e 2_{w}$ 


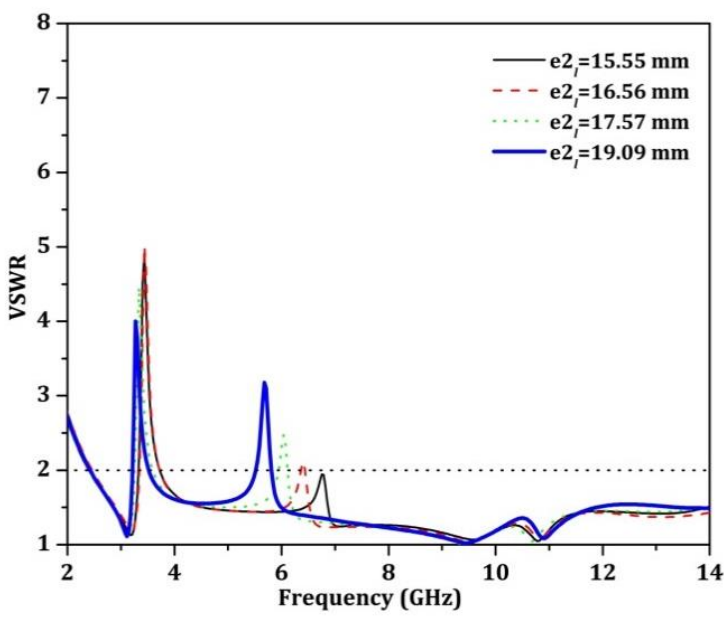

Fig. 8 Simulated VSWR curves for the different values of e $1 l$

The measured $\mathrm{E}$ and $\mathrm{H}$-plane radiation patterns at 3.11, 4.5 and $9.45 \mathrm{GHz}$ are presented in Fig. 9. From these figures, it indicates that the radiation patterns of proposed antenna are stable and omnidirectional in the H-plane and bidirectional in the E-plane.

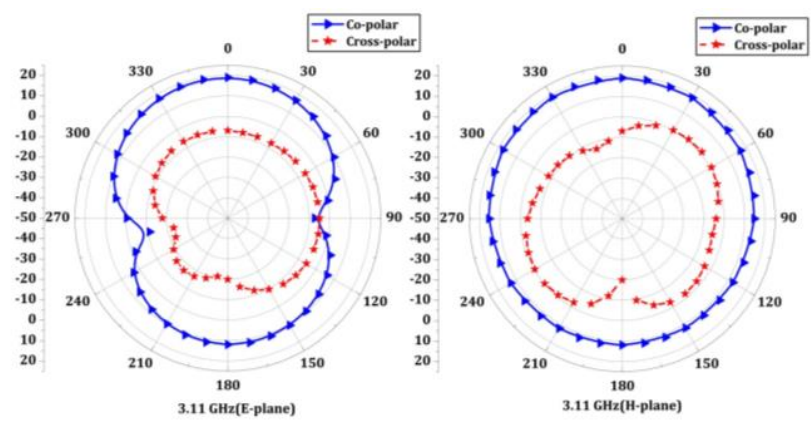

(a)
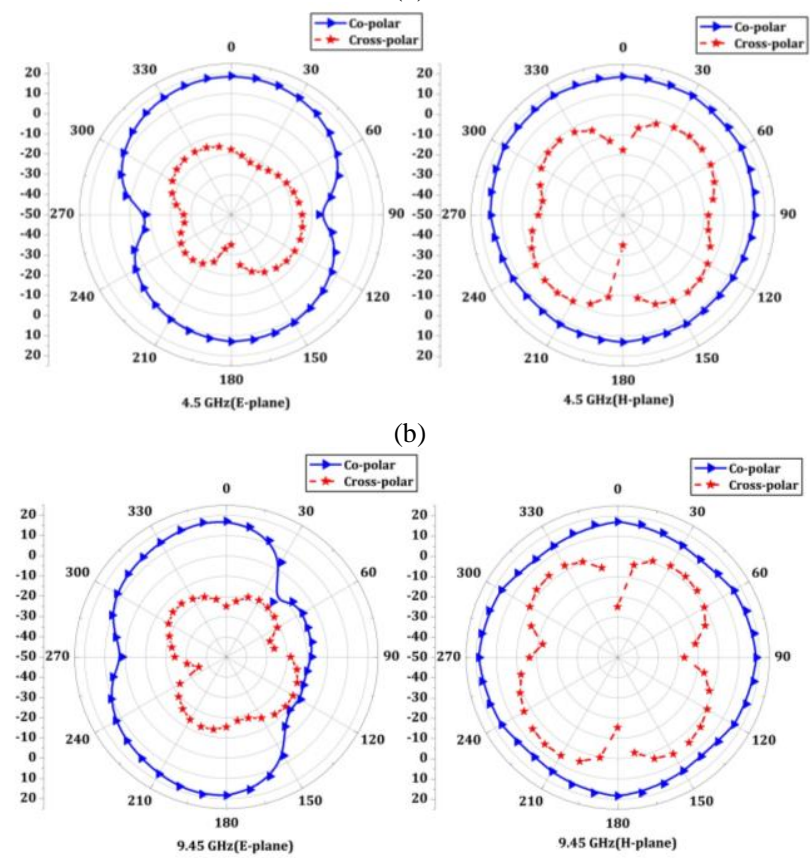

(c)

Fig. 9 . Normalized typical E-plane and H-plane radiation patterns measured at (a) $3.11 \mathrm{GHz}$, (b) $4.5 \mathrm{GHz}$ and (c) $9.54 \mathrm{GHz}$
The peak gain against the frequency of the proposed antenna is presented in Fig. 10. The gain varies from $4 \mathrm{dBi}$ to $5.2 \mathrm{dBi}$ for the UWB operating band, $-2.8 \mathrm{dBi}$ and $-4 \mathrm{dBi}$ for the rejected bands of WiMAX and WLAN range. Further, 97\% the antenna efficiency is observed and at the notched bands. The radiation efficiencies are reduced to $50 \%$ and $45 \%$ from first to second notched bands respectively. The presented result shows that the proposed antenna is successfully performed with the rejection at 3.3 $\mathrm{GHz}$ WiMAX and $5.75 \mathrm{GHz}$ WLAN.

Figure 11 shows the simulated group delay of the proposed antenna. The variation of group delay is within 1 ns throughout the UWB band except the dual notched bands at $3.3 \mathrm{GHz}$ and $5.75 \mathrm{GHz}$ in which the maximum group delay is more than $4 \mathrm{~ns}$ and $7 \mathrm{~ns}$ respectively. The group delay corresponds well to the magnitude of transmission characteristics, which indicates that the antenna has a good time-domain characteristic with small pulse distortion.

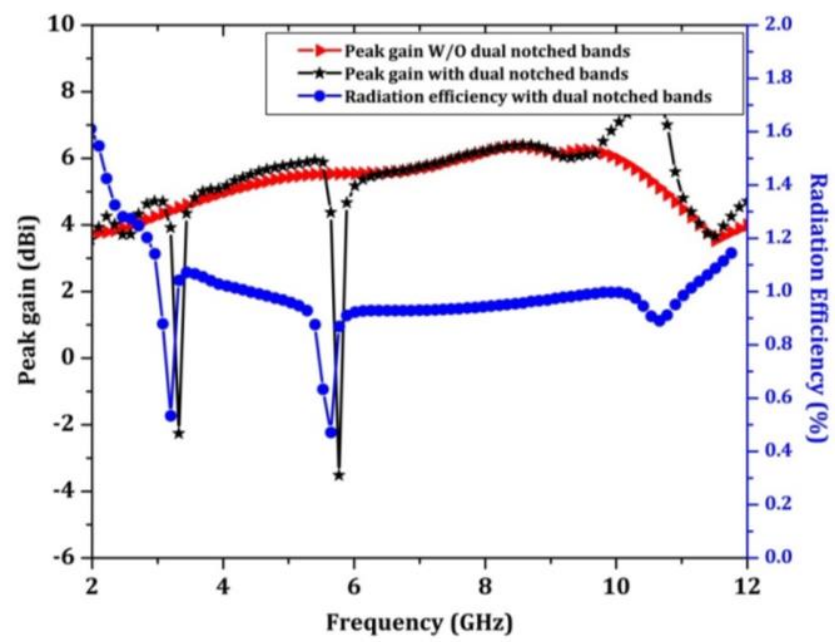

Fig.10. Peak gain and an antenna efficiency of the proposed antenna

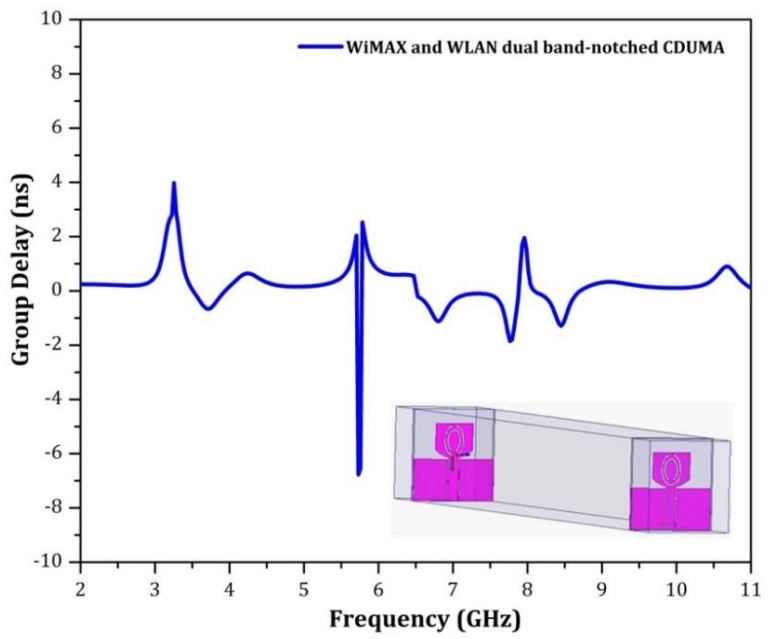

Fig. 11 Group delay variation dual band-notched UWB antenna

\section{Conclusion}

A planar UWB antenna with dual band-notched characteristics has been proposed and discussed in this paper. The antenna realized by etching the one elliptical split ring slot for WLAN on the radiating patch and another 
smaller elliptical ring slot for WiMAX on the radiating patch. The proposed UWB antenna covers the frequency from $2.7 \mathrm{GHz}$ to more than $12 \mathrm{GHz}$ with VSWR < 2 with dual notched bands at the vicinity of $3.32-3.83 \mathrm{GHz}$ and 4.96-5.43 GHz frequency range, which minimize the existing WiMAX (3.3-3.8 GHz) and WLAN (5.15-5.35 $\mathrm{GHz}$ ) operating bands. Moreover, the proposed antenna has compact in size having a good omnidirectional radiation patterns and stable gains at the entire UWB operating band.

\section{Acknowledgement}

This work is financially supported by the Jawaharlal Nehru Memorial Fund (JNMF), New Delhi to providing JN Scholarship for pursuing Doctoral Studies to the corresponding author. Special thanks to Prof. K. J. Vinoy, Department of Electrical Communication Engineering, IISc., Bengaluru, India for his assistance in radiation pattern measurements.

\section{References}

[1] Federal Communications Commission, First report and orderin the matter of revision of part 15 of the commission's rules regarding ultra-wideband transmission systems, Federal Communications Commission, ET-Docket, Washington, DC, 98-153, 2002.

[2] Schantz, H.,The Art and Science of Ultra Wideband Antennas, Artech House, 2005.

[3] Z.Q. Li, C. L. Ruan, and L. Peng, Design and analysis of planar antenna with dual WLAN band-notched for integrated bluetooth and UWB applications, Journal of Electromagnetic Waves and Applications, vol. 24, no. 13, pp. 1817-1828, 2010.

[4] M.M.S. Taheri, H.R. Hassani, and S.M.A. Nezhad, UWB printed slot antenna with bluetooth and dual notch bands, IEEEAntennas and Wireless Propagation Letters, vol. 10, pp. 255-258, 2011

[5] D.-H. Bi and Z.-Y. Yu, Study of dual stopbands UWB antenna with U-slot and V-slot DGS, Journal of Electromagnetic Waves and Applications, vol. 22, no. 17-18, pp. 2335-2346, 2008.

[6] Q.-X. Chu and Y.-Y. Yang, A compact ultrawideband antenna with $3.4 / 5.5 \mathrm{GHz}$ dual band-notched characteristics, IEEE Transactions on Antenna and Propagation, vol. 56, No. 12, 3637-3644, Dec. 2008.

[7] S. Baudha and D. K. Vishwakarma, A compact broadband printed monopole antenna with U-shaped slit and rectangular parasitic patches for multiple applications, International Journal of Microwave and Wireless Technology, pp. 1231-1235, 2016.

[8] K. Chung, J. Kim, and J. Choi, Wideband microstrip-fed monopole antenna having frequency band-notch function, IEEE Microwave and Wireless Components Lettetrs, vol. 15, no. 11, pp. 766-768, 2005.

[9] K.-H. Kim and S.-O. Park, Analysis of the Small Band-Rejected Antenna with the Parasitic Strip for UWB, IEEE Transactions on Antenna and Propagation, vol. 54, no. 6, pp. 1688-1692, 2006.

[10] S. Malekabadi, R. Attari, and M. M. Mirsalehi, Design of compact broadband microstrip antennas using coplanar coupled resonators, Journal of Electromagnetic Waves and Applications, vol. 23, no. 13, pp. 1755-1762, 2009.

[11] Zhang, Y., W. Hong, C. Yu, Z.-Q. Kuai, Y.-D. Don, and J.-Y. Zhou, "Planar ultrawideband antennas with multiple notched bands based on etched slots on the patch and/or split ring resonators on the feed line," IEEE Transactions on Antenna and Propagation, vol. 56, No. 9, 3063-3069, Sep. 2008.

[12] Ansys Corporation, Ansys High Frequency Structure Simulation (HFSS), Ver. 13, Ansoft Corporation, Pittsburgh, PA, 2010.

\section{Biography of the authors}

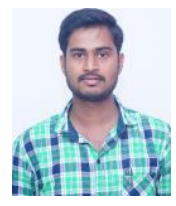

B. Satyanarayana received his M. Sc., M. Phil. and Ph.D. degrees in Applied Electronics from Dept. of Applied Electronics, Gulbarga University, Gulbarga, Karnataka, India in 2011, 2013 and 2017 respectively. $\mathrm{He}$ is presently working as a Postdoctoral Fellow under the guidance of Dr. Manoj Kumar Meshram, Associate Professor, Indian Institute of Technology (BHU), Varanasi. His research interest includes design and development of UWB, MIMO antennas.

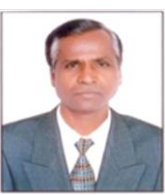

S. N. Mulgi is a Professor of Applied Electronics at Gulbarga University, Kalaburagi since 2010. He received his M.Sc., M.Phil. and Ph.D. degrees in Applied Electronics from Gulbarga University Kalaburagi in the year 1986, 1989 and 2004 respectively. He has got more than 22 years of research and teaching experience at post-graduation level. Dr. S. N. Mulgi has authored more than 260 research papers in International, National Journals, Conferences, Symposium, Seminars etc. He has engaged research work mainly in the field of Microwave Communication Engineering for the design and development of printed and microstrip array antennas. 